\title{
Parallel manipulators: state of the art and perspectives
}

\author{
J-P. Merlet*
}

パラレル・リンク・マニピュレータは, 理論的観点からもまた実用上も、過去数年間にますます多くの成果が 得られつつある. 本論文では, 最近の発展を要約し, この種のマニピュレータのさまざまな応用を紹介する.

\section{Introduction}

Let us consider a parallel manipulator as shown in Fig. 1. Two plates are connected through 6 articulated links in which a linear actuator enables to change the link lengths. By controlling these lengths we are able to control the position and orientation of the upper-plate with respect to the base plate. Usually the links are joined to the plates by universal joints for the base plate and balland-socket joints for the mobile plate.

This type of structure has been known for a long time. For example around 1800 the mathematician Cauchy studied the rigidity of an "articulated octahedron"3). More recently (1949) Gough ${ }^{35)}$ used a similar mechanism to simulate the constraints

原稿受付 1992 年 7 月 31 日

パラレルマニピュレータ: 技術の最先端と展望

* INRIA exerted on tyres. However these structures were rediscovered around 1960 as they were the most practical solution for building an active flight simulator. In 1965 Stewart ${ }^{35}$ ) illustrated the use of a parallel structure for a flight simulator. Since this time, and although Stewart's mechanism is slightly different from the one in figure 1, parallel link mechanisms are of ten referred to as "Stewart Platform".

The choice of a parallel mechanism for a simulator platform is justified by one of its obvious advantages: the high nominal load/weight ratio. Indeed the weight of a load on the platform is approximatively equally distributed on all the links i.e. one link is submitted to only $1 / 6$ of the total weight. Furthermore, the stress in the link is mostly traction-compression which is very suitable for the linear actuators as well as for the

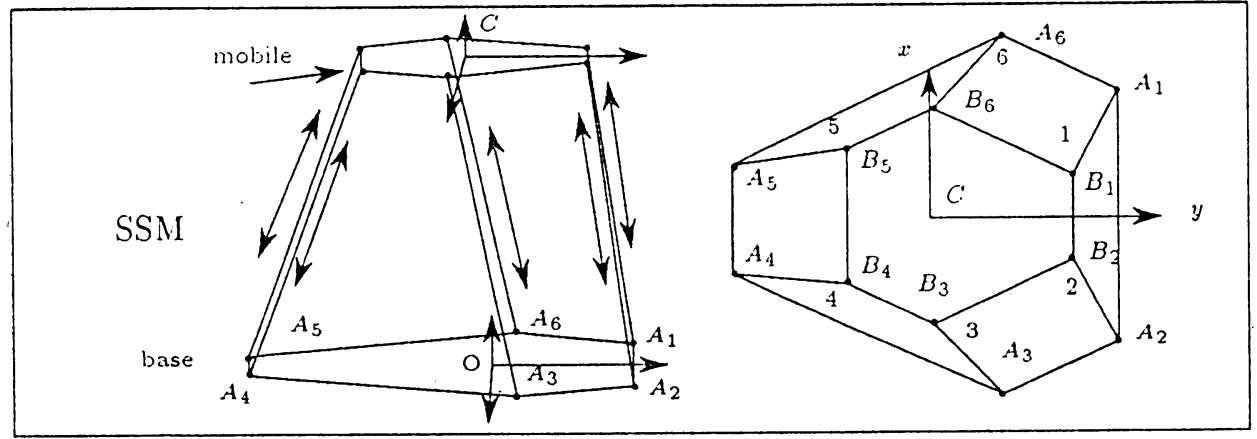

Fig.1 A parallel manipulator with 6 D. O.F. 
rigidity. This feature can be illustrated by referring to one of our parallel manipulator prototype which has a weight of $35 \mathrm{~kg}$ and a nominal load of $600 \mathrm{~kg}$ compared to one of our serial link manipulators with the identical weight and a nominal load of $1 \mathrm{~kg} \cdots$.

\section{Parallel manipulator}

Although the excellent load/weight ratio may be useful, parallel link mechanisms also present other interesting features for some robotics applications. To the best of my knowledge, a parallel manipulator was first used in a robotics assembly cell by McCallion in 197917). As an accurate manipulator is necessary to complete precise assembly tasks parallel link mechanisms are very convenient. Indeed, the position of the end-effector of a parallel manipulator is much less sensitive to the error on the articular sensors than for serial link robots. Furthermore, their high stiffness insures that the deformations of the links will be minimal and this feature greatly contributes to the high positioning accuracy of the manipulator.

Another important feature of parallel manipulators, which justifies their use for assembly tasks, is the possibility of using them as a 6 components force sensor. Indeed it can be shown that by putting a standard traction-compression force sensor in each of their 6 links it is possible to calculate the forces and torques acting on the mobile platform.

Many different designs of parallel manipulators are possible and the scientific literature on this topic is very rich. All have in common their low cost since most of the components used in a manipulator are standard although the assembly of the manipulator has to be done with care. The design is important because some features may be upgraded by an appropriate choice.

It will be seen that parallel manipulators can be used for various purposes : fast robots, light robots to be carried by a serial-link manipulator, micromanipulators or powerful robots. Their main common drawback is their usually small workspace compared to serial link manipulators.

\section{Theoretical aspects of parallel mani- pulators}

As the architecture of parallel manipulators is very different from the one used for most manipulators, most of the theoretical problems have to be reconsidered. In fact there is a strange duality between parallel link mechanisms and serial link mechanisms: a difficult (simple) problem for one kind is easily solved (with difficulty) for the other kind. This duality has yet to be explained satisfactorily, although some attempts have already been made ${ }^{38.39)}$.

\subsection{Kinematics}

Two problems can be distinguished for the kinematic aspects : inverse kinematics and direct kinematics. The inverse kinematics problem i.e. finding the link lengths for a given posture of the mobile platform (a difficult problem for serial-link mechanisms) is straightforward for parallel manipulators. Thus their control is usually very simple. On the other hand the direct kinematics problem has not be yet been solved although recent papers have given some clues on this topic ${ }^{21.28)}$. In general, this problem has more than one solution. For example, if we consider a manipulator with a triangular mobile plate, there will be up to 16 different postures of the problem for a given set of link lengths. In a very recent paper on this topic Lazard ${ }^{14)}$ showed that, in the general case, there will be no more than 640 solutions and no more than 40 if the platforms are both planar. But no closed-form solutions have been discovered except in some very special cases of manipulators with less than 6 d.o.f. In practice, iterative numerical procedures are used without any problems.

A practical way to solve the direct kinematics problem is to add orientation sensors in the links whose measurements will enable the posture of the mobile platform to be calculated ${ }^{12.1)}$.

\subsection{Dynamics}

As fast parallel manipulators can be designed the calculation of their dynamic model is necessary in order to get a satisfactory control. A full dynamic model in closed-form has yet to be established (one of the problems is that a closed-form solution 
of the direct kinematics problem will be necessary). Fortunately some assumptions can be made enabling simplified but efficient dynamics behavior to be simulated and the design of the robot can be such that these assumptions will be justified (for example links without mass). Recently many researchers have addressed this problem $4,15,16,25,26,30,32,33,36)$.

\section{3 Force-feedback control and Compliance}

As a parallel manipulator can be equipped with a 6-components force-sensor, it can carry out various tasks involving contact with its surroundings (assembly, surface following) and therefore a force-feedback scheme can be used. Successful experiments have been performed using a parallel manipulator alone ${ }^{2,23.29)}$ but interesting problems remain to be solved when both a macro and micro manipulator is used ${ }^{29)}$. An interesting point about parallel manipulators is that, although they are very rigid, passive compliance can be obtained either by using pneumatic actuators ${ }^{29)}$ or by adding elastic dampers in their links ${ }^{23)}$. In either case an appropriate choice of the position of the link's sensors enables the posture of the mobile platform to be calculated precisely whatever are the deformations of the links, which are mainly due to traction-compression stresses in the links. This has to be compared with serial link mechanisms in which the deformations of the links (mainly due to flexion) induce an unknown error in the position of the end-effector. Some researchers have also addressed the problem of determining a design which insures that, at least for some postures of the mobile platform, the stiffness matrix is diagonal ${ }^{7)}$.

\subsection{Singular configurations}

As for serial link mechanisms, a parallel manipulator can be in a singular configuration i.e. in a configuration where no articular forces (the stress in the links) can balance an external wrench applied to the mobile platform. It is important to determine the location of these configurations as, in the vicinity of a singular configuration, the articular forces will tend to infinity causing a breakdown of the manipulator. Singular configulations are characterized by the degeneration of the determinant of the inverse jacobian matrix. Although this matrix is known, the symbolic computation of its determinant yields in most cases a huge expression. Finding the closed-form of the roots of this expression seems very difficult. A numerical procedure can be used ${ }^{5)}$ but a geometrical approach enables. relationships among the position parameters characterizing a singular configuration to be found ${ }^{20)}$. An open problem is to determine if there are singular configurations inside the workspace of the parallel manipulator.

\subsection{Workspace}

In contrast to common serial link mechanisms with three intersecting wrist joint axes the workspace of a parallel manipulator cannot be decoupled in two $3 \mathrm{D}$ workspaces characterizing the possible translation motions and orientation motions. Therefore, representing this workspace is a difficult task. Usually the workspace borders are calculated for a fixed orientation and altitude of the mobile platform, either by using a numerical procedure $\mathrm{e}^{2,6)}$ or a geometrical algorithm ${ }^{822}$.

\section{6 Parallel manipulator in truss}

An interesting articulated truss can be built by joining parallel mechanism modules ${ }^{24.37)}$. This leads to light, highly redundant manipulators for which interesting kinematics and control problems have yet to be solved. These kinds of manipulators may be interesting in space applications.

\section{Practical applications}

\section{1 Research prototypes}

Although the concept of parallel manipulators is quite recent, many interesting prototypes ${ }^{1,6.9 .10 .11,12}$ 13. 27) have been proposed by various laboratories but cannot be described here and even industrial robots have been built. Only the two prototypes of parallel manipulators built at INRIA will be mentioned here. The first one is a "left hand" i.e. it is intended to be used in conjunction with a serial link robot to perform force-feedback controlled tasks. It is designed to manipulate heavy loads but has the drawback that the serial link manipulator can use the interesting features of the parallel robot only in the close vicinity of the "left hand". To overcome this problem we have designed a small parallel manipulator which is used as an active wrist of a serial link manipulator, producing a macro- 
micro roiotics system. The actuation principle of this robot is slightly different from that of the "left hand" as the links have a fixed length. Indeed, instead of changing the link lengths linear actuators are used to move the articulation points near the base along a vertical axis, leading to better orientation motions and less links interference. On the other hand, the parallel micro-manipulator developed at MEL in Japan should be mentioned, as its linear actuators have a range of a few micrometers enabling it to perform motions of a few nanometers ${ }^{2)}$.

\subsection{Commercial robots}

To the best of my knowledge the first commercial parallel manipulator, the "Gadfly", was designed by Marconi ${ }^{18)}$. The "Gadfly" is a small 6 d.o.f. manipulator intended to be used for the assembly of electronic components. Later this company designed a huge hybrid serial-parallel manipulator, the "Tetrabot"19) with a parallel module for the translation motion and a classical wrist for the orientation.

A fast 3-4 d.o.f. parallel manipulator, the "Delta" robot" ${ }^{34)}$, is now being sold by the Demaurex company. This manipulator is used for very fast pick-and-place tasks of light loads. The nice mechanical design enables it to reach high velocities and accelerations. A 6 d.o.f. manipulator based on a similar design is currently under development ${ }^{27)}$.

A French company, AICO, is currently selling a 6 d.o.f. parallel manipulator, the "SPACE 1" robot, based on Reboulet's design ${ }^{31)}$ for assembly purposes. A 6-components force sensor and a force-feedback scheme enables this robot to perform assembly tasks with a clearance of a few micrometers.

Another French company, LOGABEX, has designed a truss-robot with 4 to 66 d.o.f. parallel modules. This highly redundant manipulator is light but difficult to control.

\section{Conclusion}

Parallel manipulators present various advantages which can be useful in many robotics tasks. Although interesting theoretical problems remain to be solve $i$, the current state of the art has enabled prototypes and commercial manipulators to be designed which have successfully completed fast pick-and-place and fine assembly tasks. Although the concept of parallel manipulator is too recent and too different from the design of most classical manipulators to be widely accepted and frequently chosen by the designers of robotics systems, it is strongly felt that their use in many robotics tasks is so necessary that they. will become indispensable in the near future.

\section{References}

1) T. Arai, K. Cleary et al. Design, analysis and construction of a prototype parallel link manipulator. In IEEE Int. Workshop on Intelligent Robots and Systems, 3-6 July 1990.

2) T. Arai et al. Development of a parallel link manipulator. In ICAR, 839-844, Pisa, 19-22 June 1991.

3) A. Cauchy. Deuxième mémoire sur les polygônes et les polyèdres. Journal de l'Ecole Polytechnique, 1813.

4) W. Q. D. Do and D. C. H. Yang. Inverse dynamic analysis and simulation of a platform type of robot. J. of Robotics Systems, 5 (3) : 209-227, 1988.

5) D. Douady. Contribution à la modélisation des robots parallèles: conception d'un nouveau robot à 3 liaisons et six degrés de liberté. PhD thesis, Université Paris VI, Paris, 9 December 1991.

6) E.F.Fichter. A Stewart platform based manipulator: general theory and practical construction. The Int. J. of Robotics Research, 5( 2 ) : 157-181, 1986.

7) C. Gosselin. Kinematic analysis optimization and programming of parallel robotic manipulators. PhD thesis, McGill University, 1988.

8) C. Gosselin. Solution polynomiale au problème de la cinématique directe des manipulateurs parallèles plans à 3 degrés de liberte. Mechanism and Machine Theory, 27(2): 107-119, 1992.

9) A.Hara and K. Sugimoto. Synthesis of parallel micromanipulators. Trans. of the ASME, J. of Mechanisms, Transmissions and Automation in Design, $111: 34-39$, March 1989.

10) V.Hayward and R. Kurtz. Preliminary study of serial-parallel redundant manipulator. In 
NASA Conference on Space Telerobotics, 39-48, Pasadena, 31 January 1989.

11) J-M. Hervé and F. Sparacino. Structural synthesis of parallel robots generating spatial translation. In ICAR, 808-813, Pisa, 19-22 June 1991.

12) H. Inoue, Y.Tsusaka, and T. Fukuizumi. Parallel manipulator. In Proc. 3 rd ISRR; 321-327, Gouvieux, France, 7-11 October 1985.

13) D. Kohli, S-H Lee, K-Y Tsai, and G. N. Sandor. Manipulator configurations based on Rotary-Linear ( $\mathrm{R}-\mathrm{L}$ ) actuators and their direct and inverse kinematics. Trans. of the ASME, J. of Mechanisms Transmissions and Automation in Design, $110: 397-404$, December 1988.

14) D. Lazard. Stewart platform, 17 October-15 November 1991. Communication personelle.

15) K-M Lee and D.K.Shah. Dynamic analysis of a three-degrees-of-freedom in-parallel actuated manipulator. IEEE J. of Robotics and Automation, 4( 3 ) : 361-368, June 1988.

16) O. Ma. Direct kinematics and dynamics of a planar three-dof parallel manipulator. In ASME Design and Automation Conf., volume 3, 313-320, May 1989.

17) H. Mac Callion and D. T. Pham. The analysis of a six dgrees of freedom work station for mechanized assembly. In Proc. 5 th World Congress on Theory of Machines and Mechanisms, Montreal, July 1979.

18) Marconi. The Gadfly manipulator. Technical Report 732, Marconi Research Centre, 1985.

19) Marconi. Development of the Tetrabot robotic manipulator. Technical report, Marconi Research Centre, 1986.

20) J-P. Merlet. Singular configurations of parallel manipulators and grassmann geometry. International Journal of Robotics Research, 8( 5 ) : 45-56, 1990.

21) J-P. Merlet. Direct kinematics and assembly modes of parallel manipulators. International Journal of Robotics Research, 11(2):150162, 1992.

22) J-P. Merlet. Manipulateurs parallèles, 5eme partie: Détermination de l'espace de travail. Technical Report 1645, INRIA, 1992.

23) J-P. Merlet. Force-feedback control of parallel manipulators. In IEEE Int. Conf. on Robotics and Automation, Philadelphie, 24-
29 April 1988.

24) K. Miura and H. Furuya. Variable geometry truss and its application to deployable truss and space crane arms. In 35 th Congress of the Int. Astronautical Federation, Lausanne, 7-13 October 1984

25) Y. Nakamura and M.Ghodoussi. Dynamics computation of closed-link robot mechanisms with nonredundant and redundant actuators. IEEE Transactions on Robotics and Automation, 5( 3 ) : 294-302, June 1989.

26) F. Pierrot. Robots Pleinement Parallèles Légers: Conception Modélisation et Commande. $\mathrm{PhD}$ thesis, Université Montpellier II, 24 April 1991.

27) F. Pierrot, P.Dauchez, and A. Fournier. Hexa : a fast six-dof fully parallel robot. In ICAR, 1159-1163, Pisa, 19-22 June 1991.

28) M. Raghavan. The Stewart platform of general geometry has 40 configurations. In ASME Design and Automation Conf., volume 32-2, 397-402, Chicago, 22-25 September 1991.

29) C. Reboulet. Hybrid control of a 6 d.o.f. in parallel actuated micro-macro manipulator mounted on a Scara robot. In $3 \mathrm{rd}$ ISRAM, volume 3, 293-298, Burnaby, 18-20 July 1990. ASME Press Series.

30) C. Reboulet and T.Berthomieu. Dynamic model of a six degree of freedom parallel manipulator. In ICAR, Pisa, 19-22 June 1991.

31) C. Reboulet and A. Robert. Hybrid control of a manipulator with an active compliant wrist. In 3rd ISRR, 76-80, Gouvieux, France, 7-11 October 1985.

32) Y.Seguchi, M. Tanaka, et al. Dynamic analysis of a truss-type flexible robot arm. JSME Int. J., 32( 2) : 183-190, 1990.

33) M.Sklar and D. Tesar. Dynamic analysis of hybrid serial manipulator system containing parallel modules. Trans. of the ASME, J. of Mechanisms Transmissions and Automation in design, $110: 109-115$, June 1988.

34) F.Sternheim. Tridimensionnal computer simulation of a parallel robot. results for the Delta 4 machine. In Int. Symp. on Industrial Robots, 333-340, April 1988.

35) D. Stewart. A platform with 6 degrees of freedom. Proc. of the Institution of mechanical engineers, 180 (Part 1, 15): 371-386, 1965-66. 
36) K. Sugimoto. Kinematic and dynamic analysis of parallel manipulators by means of motor algebra. Trans. of the ASME, J. of Mechanisms Transmissions and Automation in Design, $109: 3-7$, March 1987.

37) M. Tanaka et al. Motion/configuration control of a truss-type parallel manipulator with redundancy. In Japan-USA Symposium on flexible automation, 329-336, ISCIE, Kyoto, 1990.

38) K. J. Waldron and K. H. Hunt. Series-parallel dualities in actively coordinated mechanisms. The Int. J. of Robotics Research, 10(2): 473-480, 1991.

39) V. B. Zamanov and Z. M. Sotirov. A contribution to the serial and parallel manipulator duality. In 8 th World Congress on the Theory of Machine and Mechanisms, 517520, Prague, 26-31 August 1991.

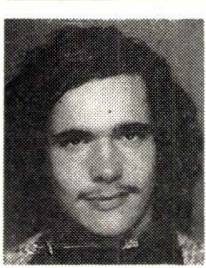

\section{J-P.Merlet}

J-P. Merlet is a senior researcher of INRIA, the French governmental Research Institute in computer science and control theory. He received Engineer degree from ENSM in 1980, completed its $\mathrm{PhD}$ in force-feedback control of robots from Paris VI University in 1986 and is a member of "La societe des amis du chateau de Mouans Sartoux". Currently he is working in one of the robotics projects at INRIA, located in Sophia-Antipolis, French Riviera. Its main research area is the use of geometry and symbolic computation tools for the study of mechanisms. He has worked on parallel manipulators for 6 years and has written a book on this topic. 